\title{
USE OF MUSCLE RELAXANTS
}

\author{
By Francis F. Foldes, M.D., \\ Director, Department of Anaesthesia, Mercy Hospital; Associate Professor of Anaesthesiology, University of Pittsburgh \\ School of Medicine, Pittsburgh, Pa., U.S.A.
}

\section{Basic Considerations}

The purpose of muscle relaxants is to provide muscular relaxation by selective depression of neuromuscular transmission without the need for deep general anaesthesia with its inherent dangers. To use these agents intelligently, it is essential to understand the physiology of neuromuscular transmission and the mode of action of the neuromuscular blocking agents.

\section{Neuromuscular Transmission}

When a nerve impulse reaches the neuromuscular junction, acetylcholine is liberated at the endplate. Acetylcholine is adsorbed to the cholinergic receptors, depolarizes the endplate, and creates the endplate potential which in turn initiates muscular contraction. Within a few milliseconds, the acetylcholine is hydrolyzed by the acetylcholinesterase present at the endplate and the endplate becomes repolarized and ready to transmit the next nerve impulse. Anything that interferes with either the depolarization or the repolarization phase of neuromuscular transmission will produce neuro-muscular block. ${ }^{1}$

\section{Neuromuscular Block}

Classification. The type of neuromuscular block of primary interest to the anaesthetist is that produced by the quaternary ammonium compounds. All these compounds act by preventing the access of acetylcholine to the cholinergic receptors of the endplate. ${ }^{1}$ Some of them, called non-depolarizing or 'competitive' relaxants, do not change the electrical properties of the endplate and cause neuromuscular block by preventing the depolarization of the endplate by acetylcholine. The depolarizing muscle relaxants produce an acetylcholine-like depolarization and for variable periods prevent the repolarization of the endplate. ${ }^{3}$ After prolonged exposure to depolarizing relaxants, the character of the block may change and become similar to a non-depolarization block. ${ }^{4}$ Under suitable circumstances, all quaternary ammonium type neuromuscular blocking agents may produce either a depolarization or a non-depolarization block. ${ }^{5}$ The type of block will depend on: I, the chemical structure of the relaxant ${ }^{6} ; 2$, the properties of the particular endplate investigated ${ }^{7}$; and 3 , the duration of exposure of the endplate to the relaxant. ${ }^{4}$

Non-depolarization Block. Certain quaternary ammonium compounds [e.g. d-tubocurarine, gallamine (Flaxedil)], under physiological circumstances, will produce a typical non-depolarization block, characterized by flaccid paralysis, not preceded by signs of stimulation, in all amphibian, avian and mammalian species investigated. The variation in the $\mathrm{mg}$. $/ \mathrm{kg}$. dose of non-depolarizing muscle relaxants between various mammals is relatively low $^{8}$ (fourfold). Ether, and to a lesser extent cyclopropane and procaine, increase the effects of non-depolarizing relaxants. The block is antagonized by acetylcholine, neostigmine (Prostigmin), edrophonium (Tensilon) and potassium.

Depolarization Block. The myoneural effect of the depolarizing muscle relaxants [e.g. decamethonium (Syncurine), succinylcholine (Scoline)] is less uniform. Depending on the sensitivity of the endplate to depolarization and the duration of exposure, the block produced may be either a typical depolarization block or similar to a nondepolarization block. In amphibians and avians, the depolarizing relaxants will produce spastic paralysis preceded by signs of stimulation. ${ }^{2}$ In mammals sensitive to depolarization (e.g. cat, man), the flaccid paralysis produced is preceded by signs of stimulation. ${ }^{2}$ In other mammals (e.g. monkey), the initial signs of stimulation may be absent. ${ }^{9}$ In mammals, sensitivity to depolarizing relaxants varies inversely with sensitivity to nondepolarizing agents. For example, the cat is more sensitive to decamethonium and relatively less sensitive to d-tubocurarine; the rat is sensitive to d-tubocurarine but less so to decamethonium. There is marked (eighty fold) species variation in the $\mathrm{mg} . / \mathrm{kg}$. dose of depolarizing relaxants in mammals. ${ }^{8}$ Ether and cyclopropane do not potentiate depolarizing muscle relaxants and acetylcholine, neostigmine and edrophonium, in- 
stead of antagonizing, potentiate their effect. ${ }^{2}, 10$ In certain mammals (e.g. rabbit) on prolonged exposure ${ }^{4}$ depolarizing relaxants produce a nondepolarization block which can be antagonized by neostigmine, ${ }^{9}$ edrophonium ${ }^{11}$ and potassium. ${ }^{4}$ In others (e.g. monkey, dog) whose endplate is more resistant to depolarization, this will occur after relatively short exposure. Parallel with the decreasing sensitivity of the endplate to depolarization, its sensitivity to non-depolarizing relaxants increases. Depending on the sequence and duration of their administration, the depolarizing and non-depolarizing relaxants may have mutually antagonistic or additive effects. Thus the administration of small doses of non-depolarizing relaxants protect against the myoneural effects of large doses of depolarizing agents. ${ }^{5}$ Similarly, depolarizing relaxants may antagonize the neuromuscular block induced by non-depolarizing relaxants. ${ }^{12}$ On the other hand, clinically ineffective doses of d-tubocurarine or gallamine will cause profound and long-lasting myoneural block after prolonged administration of succinylcholine or decamethonium. ${ }^{5,12}$ The sensitivity of the endplate to depolarization may change under pathological circumstances. After chronic denervation, non-depolarizing relaxants may produce a depolarization block ${ }^{\mathbf{1 3}}$; and in myaesthenia gravis, depolarizing muscle relaxants cause a nondepolarization block which is reversible by neostigmine.?

Because of the qualitative and quantitative species variation in response to muscle relaxants, the experimental findings in laboratory animals are not always applicable to man. Before their clinical application, the neuromuscular and other pharmacological effects of the relaxants should, therefore, be carefully studied in man. ${ }^{1}$

Of the clinically used muscle relaxants, dtubocurarine, dimethyl-tubocurarine, gallamine (Flaxedil), laudexium (Laudolissin) and benzoquinonium (Mytolon) are non-depolarizing, and decamethonium, succinylcholine (suxamethonium, Scoline, Brevedil-M, Anectine) and suxethonium (Brevedil-E) are depolarizing relaxants.

\section{Other Pharmacological Effects}

Central Effects. In anaesthetized animals, the muscle relaxants may depress the activity of the respiratory centre. ${ }^{15}$ In paralyzing doses, the clinically used relaxants have no appreciable central effects in unanaesthetized man. ${ }^{16}$ However, the possibility cannot be excluded that under pathological circumstances, the muscle relaxants may have a central depressant action in anaesthetized man.

Autonomic Effects. The autonomic effects of muscle relaxants are also due to competition with acetylcholine for the cholinergic receptors of the autonomic ganglia. After their adsorbtion to these receptors, they may either inhibit or facilitate tho transmission of ganglionic impulses. d-Tubo? curarine has the most marked autonomic effect of the relaxants in current clinical use. The gang $\stackrel{0}{\oplus}$ lionic effects of other relaxants are restricted te certain components of the autonomic nervous system. For example, gallamine has a selective inhibitory effect on the cardiac vagus and benzo@ quinonium in clinical doses stimulates, and ito larger doses inhibits, the vagus.

Respiratory Effects. Muscle relaxants may influence respiration by paralysing respiratory muscles, by depressing the activity of the respiratory centre, and by bronchoconstriction causect by histamine release. ${ }^{17}$ The sensitivity of the diaphragm to relaxants is usually less than that of other muscles. Bronchoconstriction caused bye histamine release has been observed only witho d-tubocurarine.

Circulatory Effects. In clinical doses the muscle relaxants have no appreciable effect on cardiac muscle. The circulatory effects of the relaxants are related to their autonomic effects and their histamine releasing properties, and are magie fested by changes in heart rate and blood pressư Gallamine may cause acceleration of the herg with moderate rise in blood pressure; benß̄ quinonium may decrease the heart rate. d-Tubo curarine, by inhibiting the sympathetic vaso: constrictors and liberating histamine, occasionall\% causes hypotension. The elevation of blood pressure seen after large doses of succinylcholine or after relaxant doses in light anaesthesia, is probably due to its stimulating effect on the. sympathetic system.

Histamine Release. Signs of histamine release are encountered most frequently with d-tubo 3 . curarine or laudexium. As already stated, histaming release may cause bronchospasm or hypotension.

Miscellaneous Effects. Decreased peristalsis and intestinal distension has been observed after the use of d-tubocurarine. ${ }^{18}$ The effect of other re․ㅡ. laxants on the tone and motility of the intestines is negligible.

Salivation and increased bronchial secretion may be caused by muscle relaxants, particularly by

Uterine muscle is not significantly affected b muscle relaxants. 19

Succinylcholine may cause sustained elevation of the intraocular pressure both in laborator $\bar{D}$ animals and in man. ${ }^{20}$

Muscle relaxants have a variable inhibitor $\stackrel{?}{\vec{D}}$ effect on both the true and pseudo-choline 
sterases. ${ }^{21}$ There seems to be no relationship between the anticholinesterase activity and the neuromuscular effect of the relaxants. ${ }^{21}$

\section{Fate of Muscle Relaxants}

Following intravenous administration of the relaxants, a rapid distribution equilibrium develops between the plasma and the neuromuscular junction. When the concentration of the relaxant at the endplate reaches a certain critical level neuromuscular block develops. As the concentration of the relaxant in the plasma diminishes because of excretion, decomposition and distribution into inactive tissue depots, the relaxant diffuses back from the endplate into the plasma. This rediffusion accounts for the termination of the myoneural block; there is no significant breakdown of muscle relaxants at the endplate. ${ }^{22}$

After relatively small doses of relaxants, redistribution into inactive tissue depots is primarily responsible for re-establishment of neuromuscular transmission. After doses large enough to saturate the inactive tissue depots, the role of excretion and decomposition will be primarily responsible for terminating the neuromuscular block.

Of the clinically used muscle relaxants, gallamine, benzoquinonium, laudexium and decamethonium are excreted mostly unchanged, dtubocurarine and dimethyl-tubocurarine are partly broken down and partly are excreted unchanged, and succinylcholine and suxethonium are almost completely hydrolyzed by plasma cholinesterase. ${ }^{19}$ The hydrolysis of succinylcholine occurs in two steps. First, it is hydrolyzed relatively quickly to succinylmonocholine and choline, and then much more slowly, to succinic acid and choline. Succinylmonocholine also has considerable neuromuscular blocking effect. ${ }^{23}$

\section{Antagonists of Muscle Relaxants}

Specific antagonists of decamethonium ${ }^{24}$ and succinylcholine ${ }^{25}$ are also available, but only the antagonists of the non-depolarizing muscle relaxants have clinical importance. The latter probably exert their effect by a dual mechanism: I, Inhibition of cholinesterases allowing accumulation of acetylcholine at the endplate; and 2, displacement of the muscle relaxant from the endplate where they exert a direct depolarizing action of their own. Of the clinically used antagonists, neostigmine and pyridostigmine (Mestinon) probably act mainly by the first and edrophonium by the second mechanism. Under certain circumstances, the effects of the depolarizing relaxants may also be antagonized by anticholineesterases. $^{4}, 9,11$

\section{Clinical Application} Choice of Muscle Relaxants

The choice of muscle relaxants is influenced by: I, the expected length of the operative procedure; 2 , the general anaesthetic used; and 3 , the patient's condition. For very short procedures, the agent of choice is succinylcholine or suxethonium. For procedures lasting between ro and 20 minutes, a single dose of a long-acting relaxant may be used. For prolonged muscular relaxation, succinylcholine in continuous intravenous drip of an 0.1 to 0.2 per cent. solution or fractional doses of a long-acting relaxant are recommended. In general, the use of succinylcholine offers greater flexibility. Excellent control of the degree of relaxation can also be obtained by the combined use of small doses ( 2 to $6 \mathrm{mg}$.) of d-tubocurarine and ether. ${ }^{26}$ The use of muscle relaxants in patients with altered sensitivity will be discussed later.

\section{Maintenance of Adequate Respiratory Exchange}

Adequate respiratory exchange can be achieved either by assisted or controlled respiration. In the majority of cases, assisted respiration is preferable to controlled respiration because: I, it does not interfere with the autorhythmicity of the respiratory centre; 2 , the pattern of respiration is physiological (the volume of the thoracic cage increases first, and alveoli open up early during respiration); 3 , there is less interference with venous return; 4, valuable information may be obtained regarding the degree of muscular relaxation and the depth of general anaesthesia from the respiratory rate, rhythm and depth; and 5, occasionally the apnoea produced for controlled respiration is not readily reversible postoperatively. ${ }^{27,} 28$

For controlled respiration the patient may be rendered apnoeic by the depression of the respiratory centre with general anaesthetic agents and/or hyperventilation, or the paralysis of all respiratory muscles with a relaxant and hyperventilation. Because of its more favourable circulatory effects, positive-negative pressure controlled respiration is preferable to intermittent positive pressure. ${ }^{19}$

\section{Mode of Administration}

Lack of space prevents full description of the conventional methods of the employment of muscle relaxants. However, a few important aspects of their clinical use will be given.

Use of Long-acting Relaxants. The dose of the long-acting relaxants depends inter alia on the general anaesthetic agent used. In general, larger doses are required when anaesthesia is maintained by nitrous-oxide-oxygen supplemented by thiopentone alone, or in combination with analgesics 
TABLE I

The Recommended Doses of Relaxants with Varigus Anaesthetic Agents

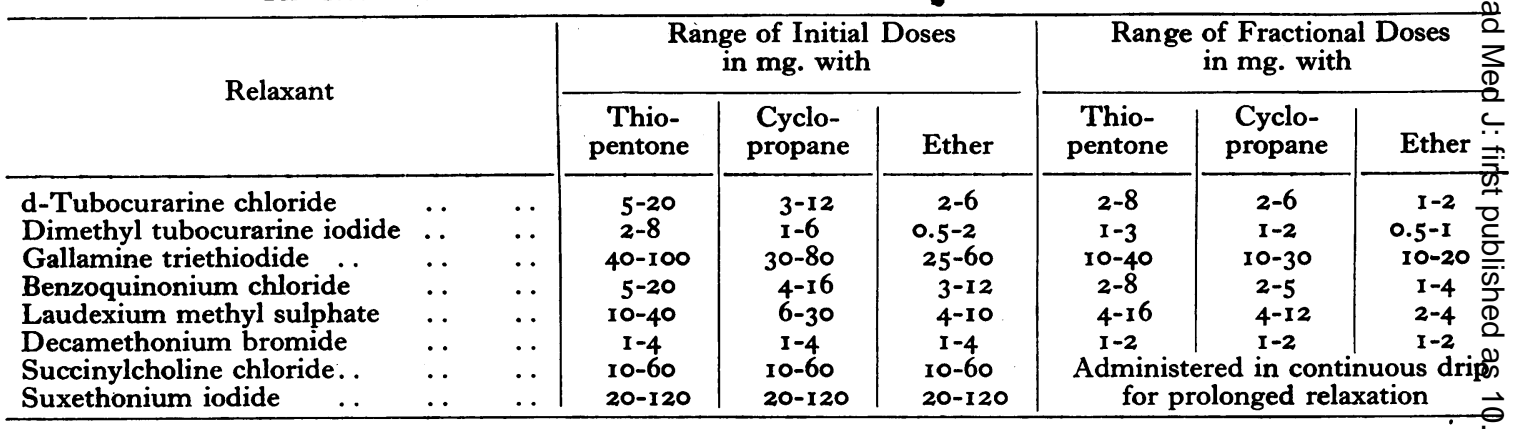

than when anaesthesia is maintained by ether or cyclopropane. The recommended initial and fractional doses of the long-acting relaxants with different methods of general anaesthesia are given in table $\mathrm{I}$.

The initial and first fractional doses of the longacting relaxants are chosen empirically and correct dosage depends on the experience of the anaesthetist. If the last dose of the relaxant is administered at the start of the peritoneal closure, satisfactory spontaneous respiration will be present at the termination of surgery in the majority of cases. With careful management, post-operative respiratory depression will be encountered in not more than 2 per cent. of patients. ${ }^{29}$

The Use of Succinylcholine. The single dose of succinylcholine is about $0.6 \mathrm{mg} / \mathrm{kg}$. In patients with known or suspected low plasma cholinesterase level, the initial dose should be markedly decreased. Larger doses of succinylcholine (I.O to $1.5 \mathrm{mg}$. $/ \mathrm{kg}$.) are recommended, however, for the treatment of laryngeal spasm where an inadequate response to a smaller dose may endanger the patient's life.

When succinylcholine is used to produce prolonged muscular relaxation, an 0.1 to 0.2 per cent. solution is administered, at first rapidly, in continuous intravenous drip. ${ }^{19}$ As soon as the decrease of the tidal volume indicates the onset of muscular relaxation, the drip is slowed down and endotracheal intubation is performed. Following intubation, depending on whether the patient is breathing spontaneously or not, the drip is temporarily stopped or adjusted to the rate expected to maintain adequate relaxation. If the selected rate is excessive and causes apnoea, the drip is temporarily discontinued and restarted at a slower rate after the return of spontaneous respiration. When the selected rate fails to give satisfactory relaxation, the drip is run faster until relaxation becomes adequate and then continued at a rate higher than the one which failed to give relaxation. With this technique, adequate muscular relaxation can be maintained without the dangers of prolonged posfs operative apnoea. When controlled respiration being used, there is a danger of administering excessive doses of succinylcholine. This can avoided by periodically discontinuing the drip and watching for signs of return of spontaneows respiration.

The Combined Use of Relaxants. Depending o the sequence of administration, the combined use of depolarizing and non-depolarizing relaxants may be permissible or extremely dangerous. objections can be raised to using d-tubocurarine gallamine for the maintenance of surgical res laxation, after a single dose of succinylchofife given for endotracheal intubation. On the other hand, the use of succinylcholine to facilitate toneal closure after administration of d-tubocurarine or gallamine is inadvisable. Under sus circumstances, because of the pronounced antage nistic effect of subparalytic doses of non-depolarioing relaxants against depolarizing agents, ${ }^{5}$ e. cessive doses of succinylcholine may be necessary to obtain adequate relaxation. Prolonged apnoêa may result from these excessive doses. Adequate relaxation can be obtained with small doses d-tubocurarine (0.10 to $0.15 \mathrm{mg}$. $/ \mathrm{kg}$.) or galla mine $(0.50$ to $0.75 \mathrm{mg} . / \mathrm{kg}$.) after the prolongeg administration of succinylcholine. ${ }^{5}$ This metho, however, is still experimental and is not recons mended for gene:ral clinical use.

The use of fixed mixtures of relaxants and barb울turates $^{31,32,33}$ or analgesics ${ }^{34}$ has been recon mended. Although these methods may have practical advantages, their application cannot justified by pharmacological considerations and indeed, may be dangerous. The relaxant and barbiturate or analgesic requirements of patients frequently vary in opposite directions and the administration of fixed mixtures may result $\frac{\mathbb{1}}{10}$ gross overdosage with either component. ${ }^{35}$

Use of Relaxants in Patients with Altered Sensitivi旸 Besides the muscularity of the patient, the 
TABLE 2

The Mg./Kg. Doses of Muscle Relaxants in Infants AND CHILDREN

\begin{tabular}{|c|c|c|}
\hline Relaxant & $\begin{array}{c}\text { Initial } \\
\text { Dose }\end{array}$ & Fractional Dose \\
\hline $\begin{array}{l}\text { d-Tubocurarine* } \\
\text { Gallamine } \\
\text { Decamethonium } \\
\text { Succinylcholine }\end{array}$ & $\begin{array}{l}0.10-0.20 \\
1.00-1.50 \\
0.05-0.08 \\
0.40-0.80\end{array}$ & $\begin{array}{c}0.05-0.10 \\
0.30-0.50 \\
0.02-0.03 \\
\text { In continuous } \\
\text { intravenous drip }\end{array}$ \\
\hline
\end{tabular}

* With ether the dose of d-tubocurarine should be reduced to one-fifth to one-third of the above dose.

relaxant requirements are also influenced by age and by various pathological conditions.

The recommended ${ }^{19} \mathrm{mg} . / \mathrm{kg}$. doses of relaxants for the newborn and young children are shown in table 2.

In the aged, the dose of relaxants, as that of other drugs, will depend on the patient's physical condition. In general, dosage should be reduced by one-third to one-half. In doubtful cases, a small test dose may be tried.

The myaesthenic patient is extremely sensitive to non-depolarizing relaxants ${ }^{36,37}$ and with the exception of the affected muscles, is resistant to depolarizing agents. ${ }^{38}$ Nevertheless, because of the incalculable effects of the depolarizing agents on the involved muscles, the use of very small doses of non-depolarizing relaxants is recommended. A test dose of $0.75 \mathrm{mg}$. of d-tubocurarine or $5.0 \mathrm{mg}$. of gallamine should be administered. If adequate relaxation does not develop within 4 minutes, the dose should be repeated at 5-minute intervals until adequate relaxation is obtained. Residual effects of the nondepolarizing relaxants can be antagonized at the termination of surgery by edrophonium (Io to 20 mg.) or neostigmine (I.0 to $2.0 \mathrm{mg}$.) preceded by atropine. Ether, because of its effect on the myoneural junction, is contraindicated in myaesthenic patients.

Patients with severe fluid and electrolyte disturbances are usually sensitive to both the depolarizing and non-depolarizing relaxants. The long-acting agents should be administered cautiously in repeated small doses, allowing sufficient time between doses for the maximal effect to develop, until relaxation is obtained. With succinylcholine, slow infusion of an 0.1 per cent. solution is recommended. Whatever agent is used, apnoea should not be allowed to develop for under these conditions it is frequently prolonged and occasionally irreversible. ${ }^{28}$

Patients with liver disease are often sensitive to succinylcholine ${ }^{39}$ (the breakdown of which depends on cholinesterase manufactured by the liver), and may show decreased sensitivity to nondepolarizing relaxants. ${ }^{40}$ In clinical practice, how- ever, increased sensitivity to non-depolarizing relaxants may also be encountered ${ }^{19}$ probably because of the poor physical condition of many of these patients. Consequently, it is advisable to use both types of relaxants cautiously in the presence of liver damage.

In patients with kidney disease the duration of action of those relaxants which are primarily dependent on urinary excretion (e.g. decamethonium, gallamine, benzoquinonium) may be unduly prolonged. These agents should, therefore, be administered in smaller and less frequent doses than in normal individuals.

\section{Complications of the Use of Relaxants}

Most of the complications encountered with muscle relaxants are due to the use of excessive dosage. The most serious of these complications is prolonged post-operative apnoea caused by large doses of relaxants used in conjunction with controlled respiration, or given for the facilitation of peritoneal closure. As already mentioned, the administration of succinylcholine after d-tubocurarine or gallamine may also precipitate this complication. As with any other complication, prevention is preferable to treatment. When the apnoeic technique is used, especially if this is maintained by the continuous infusion of succinylcholine, the anaesthetist should make certain at intervals that no more relaxant is used than is necessary to paralyze all the respiratory muscles.

When apnoea is encountered at the termination of surgery, it must be ascertained that it is due to the paralysis of the respiratory muscles and not to other causes. The latter may include reflex breath holding due to stimulation by the endotracheal tube in the lightly anaesthetized patient, central depression by other agents used and hypocapnoea caused by hyperventilation.

The treatment of the apnoea caused by relaxants will depend on the type of agent used. After nondepolarizing relaxants, io to $20 \mathrm{mg}$. of edrophonium should first be tried. If this only has a temporary effect, 0.75 to $\mathrm{I} .5 \mathrm{mg}$. of neostigmine preceded by 0.4 to $0.6 \mathrm{mg}$. atropine should be given intravenously. If the first dose of neostigmine results in partial recovery, additional small ( $0.5 \mathrm{mg}$.) doses can be given 5 minutes apart. Tidal volume must be tested after each dose. Further doses should be discontinued when no improvement resulted from the administration of the previous dose. Large doses of neostigmine, because of their effects on the coronaries, may be dangerous, especially in cardiac patients. Furthermore excessive doses, instead of antagonizing the non-depolarization block, may cause a persistent acetylcholine block. If edrophonium or neostigmine is not effective, 0.3 per cent. $\mathrm{KCl}$ may be 
administered at 80 to 100 drops per minute. A uretheral catheter should be inserted before the start of the $\mathrm{KCl}$ administration. In the absence of urinary excretion, $\mathrm{KCl}$ administration should be avoided to prevent hyperkalemia. As a last measure, diuresis may be provoked by an osmotic diuretic (e.g. 50 to $100 \mathrm{ml}$. of 50 per cent. dextrose or sucrose) given intravenously. Controlled respiration, with alternating positive-negative pressure, should be maintained as long as necessary. Recovery of spontaneous respiration may occur after many hours.

When prolonged apnoea is encountered after succinylcholine, treatment at first should be expectant. If recovery does not start in 20 to 30 minutes, it is possible that succinylcholine produced a non-depolarization block. ${ }^{5}$ This should be treated first by edrophonium and then if this is temporarily effective, by atropine and neostigmine. If edrophonium is ineffective, neostigmine should not be tried because if the apnoea was caused by some other mechanism, neostigmine might deteriorate the situation. ${ }^{41}$ The administration of $\mathrm{KCl}$ and the production of diuresis should be tried when prolonged succinylcholine apnoea is refractory to anticholinesterases.

The treatment of prolonged apnoea after the combined use of non-depolarizing and depolarizing relaxants should follow along the same lines as described above.

\section{Miscellaneous Use of Relaxants}

Besides their use for the production of surgical relaxation, the muscle relaxants have other important therapeutic applications. Of these, from the point of view of the anaesthetist, their use in electroshock therapy and the treatment of tetanus are the most important.

The diagnostic use of relaxants in myaesthenia gravis, because of its dangers, has been almost completely replaced by the use of edrophonium. Discussion of the therapeutic and diagnostic use of relaxants is beyond the scope of this brief papet The interested reader is referred for information to other sources. ${ }^{19}$

I. FOLDES, F. F. (1954), Brit. F. Anaesth., 26, 394.

2. PATON, W. D. M., and ZAIMIS, E. J. (1952), Pharmacol. Rev $\overrightarrow{\overline{\bar{S}}}$ $4,219$.

3. BURNS, B. D., and PATON, W. D. M. (195I), f. Physioge II5, 4I.

4. JENDEN, D. J., et al. (195i), F. Pharmacol., 103, 348.

5. FOLDES, F. F., et al. (1957), Anesth. Ef Analg., 36, (5) 23.

6. BOVET, D. (1951), Ann. N.Y. Acad. Sci., 54, 407.

7. ZAIMIS, E. J., et al. (1952), Nature, 170, 617.

8. PATON, W. D. M., and ZAIMIS, E. J. (1949), Brit. F. Phare macol., 4, 381 .

9. ZAIMIS, E. J. (1953), Ұ. Physiol., 122, 238.

10. RANDALL, L. O. (1951), Ann. N.Y. Acad. Sci., 54, 460.

11. FOLDES, F. F., et al. (1957), f. Pharmacol, 119, 145.

12. BRENNAN, H. J. (1956), Brit. F. Anaesth., 28, 159.

14. BULBRING, E., and DEPIERRE, F. (1949), Brit. F. Phars macol., 4, 22.

15. ELLIS, C. H., et al. (1952), Ұ. Pharmacol., 106, 353

16. SMITH, S. M., et al. (1947), Anesthesiology, 8, 1.

17. LANDMESSER, C. N. (1947), Ibid., 8, 506.

18. GROSS, E., and CULLEN, S. C. (1945), Ibid., 6, 231.

19. FOLDES, F. F. (1957), 'Muscle Relaxants in Anesthesiology(u Ch. C. Thomas, Springfield, Ill., U.S.A.

20. LINCOFF, H. A., et al. (1955), Amer. F. Ophthal., 40, 501.

21. FOLDES, F. F., et al. (1957), $\mathcal{F}$. Pharmacol., 119, 130.

22. FOLDES, F. F. (1956), Proc. World Congr. of Anesth., p. 310, Scheveningen, Sept. 5-10, 1956.

23. FOLDES, F. F., et al. (1954), Brit. med. F., 1, 967.

24. VANDAM, L. D., et al. (1953), Anesth. Eீ Analg., 32, 113.

25. ELLIS, C. H., et al. (1953), Feder. Proc., 12, 39.

26. KEUTMANN, E. (1954), Nord. Med., 51, 823.

27. DRIPPS, R. D. (1953), Ann. Surg., 137, 145.

28. HUNTER, A. R. (1956), Brit. med. F., 2, 919.

29. FOLDES, F. F., et al. (1952), f. Amer. med. Ass., 150, I 55

30. HODGES, R. J. H. (1953), Lancet, I, 143.

31. BAIRD, J. W. (1947), Anesthesiology, 8, 75 .

32. ORGANE, G. (1949), Lancet, 1, 733.

33. EVANS, F. T., and GRAY, P. W. S. (1953), Anaesthesia, 8, 104을

34. LANCASTER, F. M., and LEVIN, J. (1956), Brit. med. f? I, 38I.

35. FOLDES, F. F., and MACHAJ, T. S. (1951), Anesthesiology

36. BENNETT, A. E., and CASH, P. T. (1943), Dis. nerv. Syst 4, 299.

37. DUNDEE, J. W. (1951), Brit. F. Anaesth., 23, 39.

38. CHURCHILL-DAVIDSON, H. D. and RICHARDSON

A. T. (1952), Neurol., Neurosurg. \& Psychiat., 15, 129.

39. FOLDES, F. F., et al. (1956), Anesthesiology, 17, 559.

40. DUNDEE, J. W., and GRAY, T. C. (1953), Lancet, $2,16$.

41. FOLDES, F. F., et al. (1956), Anesth. Eீ Analg., 35, 609.

\section{RUTHIN CASTLE, NORTH WALES}

A Clinic for the diagnosis and treatment of Internal Diseases (except Mental or Infectious Diseases). The Clinic is provided with a staff of doctors, technicians and nurses.

The surroundings are beautiful. The climate is mild. There is central heating throughout. The annual rainfall is $\mathbf{3 0 . 5}$ inches, that is less than the average for England.

The Fees are inclusive and vary according to the room occupied.

For particulars apply to THE SECRETARY, Ruthin Castle, North Wales. 